\title{
The Elidice: new instrument for visual acuity self-screening
}

\author{
K. ARundale, D. J. FAulkner, AND R. A. Weale \\ From the Department of Visual Science, Institute of Ophthalmology, Judd Street, London WCIH $9 Q S$
}

SUMMARY A compact electronic device which enables the user to determine for himself whether his visual acuity reaches a chosen standard has been constructed at a cost of $£ 25$. The instrument provides a test which requires the observer to respond to the orientation of a sequence of red Landolt-Cs and which takes under five minutes to complete. 'Crowding' effects associated with conventional letter charts are avoided and the test does not discriminate against astigmatic observers. One hundred observers were tested on both the new instrument (the Elidice) and a standard Snellen chart under clinical conditions. The overall agreement between the two tests was $87.8 \%$, with the Elidice having an over-referral level of $10.7 \%$ and an under-referral level of $1.5 \%$ as compared with the letter chart. This makes the Elidice particularly suitable for the regular screening of laser users for reduced visual acuity due to macular damage.

This paper describes a relatively simple, inexpensive instrument specifically designed to enable users of lasers to monitor their central visual acuity once their zero line has been established in a clinical examination. In general, it provides a self-screening test for checking whether visual acuity reaches a predetermined standard-as required, for example, in the British number-plate test which has to be passed by drivers of motor vehicles. Previous authors (Crossman et al., 1970; Decker et al., 1975) have described instruments for automatically measuring visual acuity. The earlier system requires a computer to control the test, and the mechanical complexity and high component count of the latter instrument make it expensive to produce. For testing to a predetermined standard a simpler instrument is desirable.

The test is based on the well-known Landolt-C (Landolt, 1899), which can be presented with its gap in one of several positions; recognition of the gap orientation implies that the ' $C$ ' can be resolved. This character provides a suitable test of central visual acuity (which is most likely to deteriorate with laser damage) and is simple to produce as a self-luminous target, so that it can be used under rigidly controlled conditions of illumination.

The development of the Elidice was supported by a Medical Research Council project grant to R.A.W. K.A. is in receipt of an MRC research studentship

Address for reprints: Professor R. A. Weale, Department of Visual Science, Institute of Ophthalmology, Judd Street, London WC1H 9QS
The instrument (Fig. 1) is called the Elidice (from an acronym for light-emitting diode $\mathrm{C}$ ). The prototype was designed for 15 presentations of the target. A light on the response panel indicates whether the observer has passed the test (by 13 or more correct responses) or failed (by 3 or more incorrect responses). The probability of passing the test by pure guesswork is $0.00009 \%$, as determined by the binomial distribution.

\section{System description}

The target consists of a circular array of 12 red diffused light-emitting diodes (LED) (Litronix RLT1). During the test presentation eight LEDs providing the fixed segments are always illuminated. Three of the other four LEDs, providing the test segments-corresponding to top, bottom, left, and right in the array-are also illuminated, to produce the Landolt-C display. The blank test segment is chosen randomly.

Although it is possible to make this choice with a pseudorandom sequence generator, the requirements of a reasonable sequence length and a one-offour output (rather than the usual binary code) would make for complex circuitry. Instead, a simpler system is used. An oscillator runs continuously between test presentations and its output is divided by a modulo- 4 counter. The counter outputs are decoded by gates to select one of the four test segments. During the presentation the oscillator is 


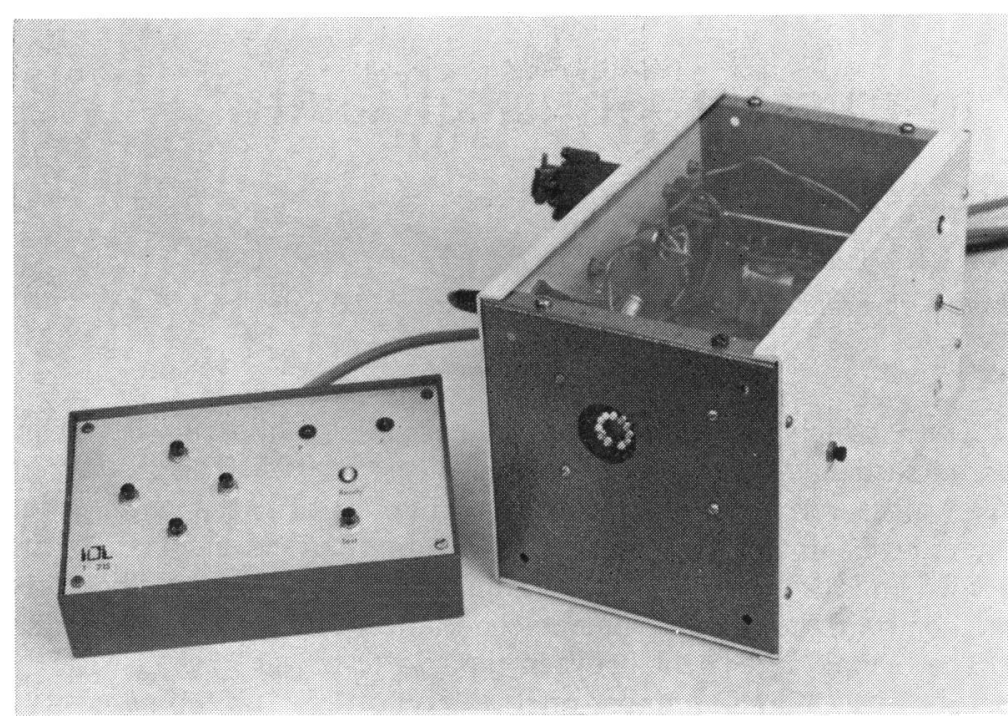

Fig. 1 The Elidice, showing response panel (left) and $L E D$ target

stopped to produce a stationary display. The test sequence is determined by the time intervals between successive presentations. By setting the oscillator frequency to about $10 \mathrm{kHz}$ it is impossible for the observer to produce a predictable sequence.

A block diagram of the system is shown in Fig. 2. Initial conditions are established by pressing the 'reset' key. The master reset pulse clears the error and answer counters, resets the input and result latches, and illuminates the 'ready' indicator. Pressing the 'test' key sets the input latch, stops the oscillator, and resets the answer latch. The 'ready' indicator is extinguished and, after a short delay to allow the system to settle, the display monostable is triggered and illuminates the target.

If an 'answer' key is pressed the response is detected by the answer gate and entered in the answer latch. The answer is compared with the test segment signal and, if wrong, it is counted in the error counter. At the same time the answer counter is incremented and, after a short delay, the display monostable reset. This turns off the display, resets the input latch, turns on the 'ready' indicator, and starts the oscillator again. If there is no response from the observer the display monostable resets itself after about three seconds and the contents of the counters do not change. Spurious counts are avoided by accepting answers only while the display is on, and the 'check answer' comparison is accepted only when an answer key has been pressed.

If the error count exceeds two the result latch is set to 'fail'. When 15 responses have been recorded by the answer counter the input gate is disabled to stop the test and the 'pass' or 'fail' indicators are enabled to display the test result.
The prototype uses a total of 15 CMOS logic integrated circuits and is mounted in a $225 \times 135 \times$ $135 \mathrm{~mm}$ box, with a remote response panel carrying the 'test' and 'answer' keys and the 'pass', 'fail', and 'ready' indicators. The total component cost was about $£ 25$.

\section{Clinical tests}

The Elidice was evaluated in comparison with a standard Snellen letter chart internally illuminated with four 25-W light bulbs. The target LEDs were operated at a current of $10 \mathrm{~mA}$, giving a typical luminance of $0.4 \mathrm{mcd}$ at $650 \mathrm{~nm}$. All the clinical tests were performed with a background illumination of 0.1 lux in the refraction clinic of Moorfields Eye Hospital as an extension to, and under the same lighting conditions as, the refraction examination. One hundred volunteer staff and patients comprising 42 males and 58 females served as observers. The total age range was 9 to 86 years, with 55 observers under, and 45 over, 40 years of age. The tests were conducted under monocular conditions with the fellow eye occluded, and to obtain additional data some persons were tested without their usual lens corrections. This brought the total number of tests to 205.

Viewing distances of 6 and $10 \mathrm{~m}$ were used with the Snellen chart and the Elidice respectively. At $10 \mathrm{~m}$ the gap in the ' $\mathrm{C}$ ' subtends the same angle at the eye as the critical dimension of the letters on the 1.0 (6/6) line of the letter chart-that is, one minute of arc. Thus a person with 1.0 acuity or better, as measured by the Snellen test, should pass on the Elidice, whereas one with an acuity of 0.67 


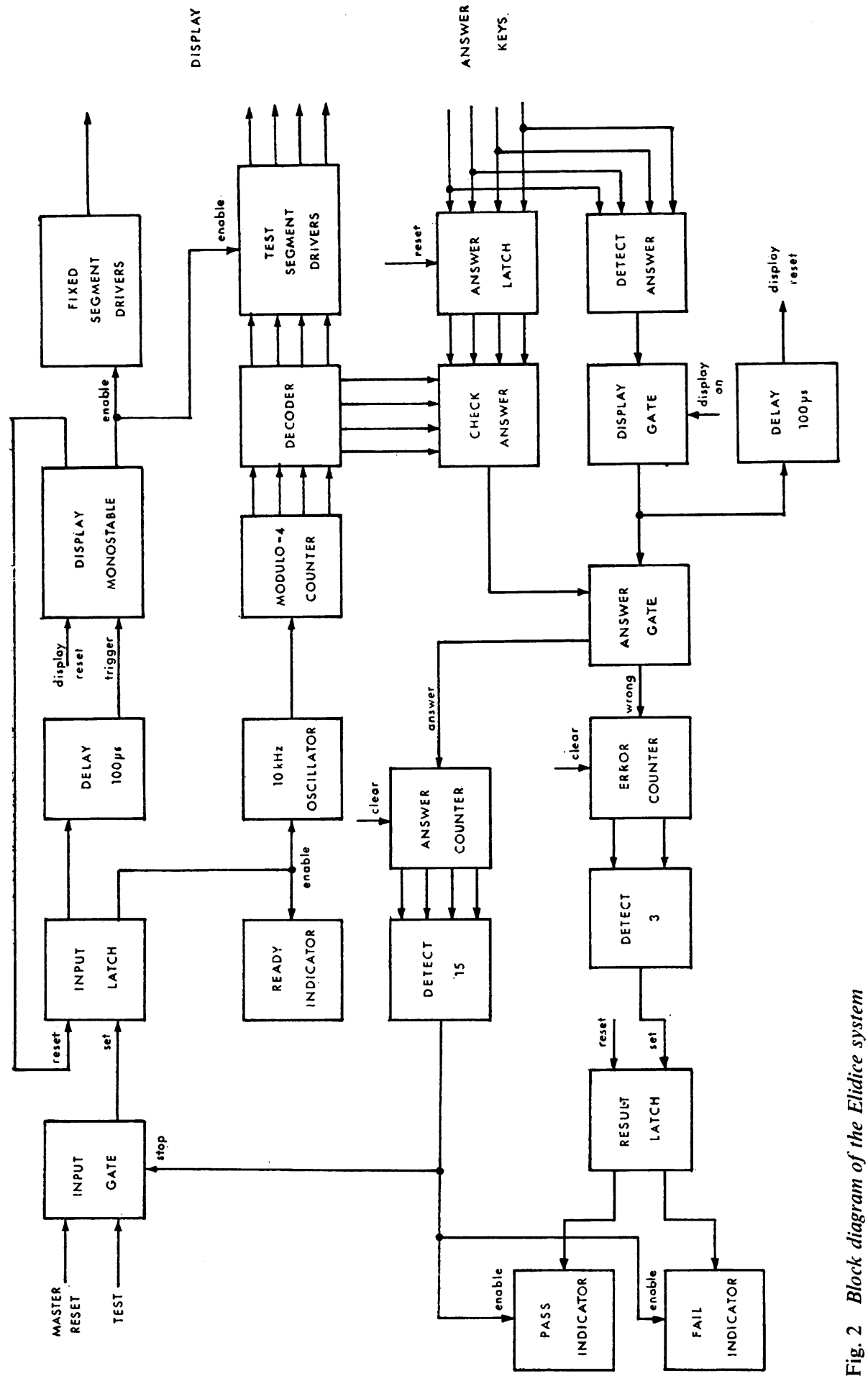

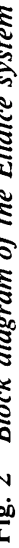


(6/9) or worse should fail. The instrument agreement is defined as the percentage of evaluations which satisfy these criteria.

\section{Results}

The overall instrument agreement between the Elidice and the Snellen chart was $87.8 \%$, with the new test having an over-referral level of $10.7 \%$ and an under-referral level of $1.5 \%$ when compared with the Snellen chart. The percentage of eyes passing the Elidice test as a function of their Snellen acuity is given in Table 1 together with corresponding $\chi^{2}$ values comparing the number of eyes passing on the Elidice with the number failing the test. At all levels of acuity the probability of there being no correlation between an observer's performance in the Elidice test and his performance in the Snellen letter test was smaller than 0.02 .

Non-parametric statistical procedures $\left(\chi^{2}\right.$ test, Fisher exact probability test) were applied to the data to see if particular groups of observers (that is, males $v$. females, staff $v$. patients, under $40 \mathrm{~s} v$. over 40s) were preferentially passing or failing on the Elidice; $\chi^{2}$ values (Table 2 ) suggest that men with acuities of 1.0 or better were more likely to pass the Elidice test than women with acuities of 1.0 or better $(\mathrm{P}<0.02)$. Table 2 also indicates that patients with acuities less than 1.0 were more likely to fail on the Elidice than staff with the same acuities $(P<0.01)$. The remaining values of $\chi^{2}$ presented in Table 2 are not significant at the 0.05 level. In all cases the Fisher exact probability test led to the same conclusions as the $\chi^{2}$ tests.

Some of those observers with acuities of 1.0 or better were colour-defective or wore optical corrections greater than 4 dioptres. However, any difference in the ability of these groups to pass the Elidice test compared with colour-normals and those wearing corrections smaller than 4 dioptres is

Table 1 Percentage of eyes passing on the Elidice as a function of their Snellen acuity

\begin{tabular}{clll}
\hline $\begin{array}{l}\text { Snellen } \\
\text { acuity }\end{array}$ & $\begin{array}{l}\text { \% passing } \\
\text { on Elidice }\end{array}$ & $\chi^{2}(D F=1)$ & $\begin{array}{l}\text { Significance } \\
(P)\end{array}$ \\
\hline 1.20 & 88.9 & 54.44 & $<0.001$ \\
1.00 & 70.0 & 6.40 & $<0.02$ \\
0.67 & 5.4 & 29.43 & $<0.001$ \\
0.50 & 0 & 11.00 & $<0.001$ \\
0.33 & $7.1 *$ & $10.29 *$ & $<0.01 *$ \\
$\leqslant 0.25$ & 0 & 13.00 & $<0.001$ \\
\hline
\end{tabular}

* passing is zero when 1 amblyopic eye is excluded $\left(\chi^{2}=14.00\right.$, $\mathbf{P}<0.001)$. See text
Table 2 Statistical evaluation of differences among observers in their ability to pass on the Elidice $(D F=1)$

\begin{tabular}{|c|c|c|c|c|c|c|}
\hline \multirow{2}{*}{$\begin{array}{l}\text { Snellen } \\
\text { acuity }\end{array}$} & \multicolumn{2}{|c|}{ Male/female } & \multicolumn{2}{|c|}{ Staff/patients } & \multicolumn{2}{|c|}{$\leqslant 40 />40$} \\
\hline & $x^{2}$ & $\begin{array}{l}\text { Significance } \\
(P)\end{array}$ & $\chi^{2}$ & $\begin{array}{l}\text { Significance } \\
(P)\end{array}$ & $x^{2}$ & $\begin{array}{l}\text { Significance } \\
(\boldsymbol{P})\end{array}$ \\
\hline$\geqslant 1.00$ & 5.69 & $<0.02$ & 1.66 & $<0.20$ & 0.86 & $<0.50$ \\
\hline$<1.00$ & 0.05 & $<0.90$ & $7 \cdot 49 *$ & $<0.01$ & 0.87 & $<0.50$ \\
\hline
\end{tabular}

* $\chi^{2}=0 \cdot 11, P<0.80$ when 1 amblyopic eye is excluded (see text)

not significant at the 0.05 level ( $\chi^{2}$ comparing colournormals with colour-defectives $=0.00045 ; \mathrm{P}<0.99$; comparing larger optical corrections with smaller corrections $=1 \cdot 27 ; \mathrm{P}<0 \cdot 3$ ).

\section{Discussion}

Most observers had little difficulty in performing the test, which takes under five minutes to complete. The most common problem related to the need to look up at the target and then down at the response panel to record an answer. Some elderly patients were arthritic and could not always respond sufficiently quickly. These problems could be alleviated by lengthening the display time to perhaps. 5 or 10 seconds and mounting the response panel in the same plane as the target. Clearly, however, an elementary level of manual dexterity is needed.

The clinical trials show that the Elidice is a slightly more severe test than the Snellen chart, but this is. desirable in a screening test. The known superiority of men in visuo-spatial tasks (Coltheart et al., 1975). is reflected in the data for observers with good acuity. The Elidice requires the observer to respond manually as opposed to verbally in the case of the Snellen chart. For observers with poor acuity (less than 1.0) the data indicate that staff are more likely to pass on the Elidice than patients. Of the six staff eyes with poor acuity, however, one was amblyopic and could read letters at the beginning and end of each line down to $1 \cdot 2$, although the overall Snellen acuity was reduced to 0.33 by the 'crowding' phenomenon (Stuart and Burian, 1962). Crowding effects are absent in the Elidice test, which was passed by the amblyopic eye. If the data for this eye are neglected in the staff/patient comparison the differences are no longer significant at the 0.05 level (Table 2). This eye is also responsible for the nonzero percentage of eyes with a Snellen acuity of 0.33 passing on the Elidice (Table 1).

The present system enables an observer to pass the test by responding to only one orientation of the display, since a failure to answer is not recorded. This arrangement is suitable for a screening test for laser damage, since astigmatic observers can choose 
to respond only to those orientations which they can see clearly. Nevertheless, for some applications a forced choice test may be preferable, and this can be achieved by simple modifications to the answer gates and the result latch circuitry, so that the instrument counts correct answers and test presentations rather than wrong answers and responses, as in the present system.

The prototype displays the result of the test by illuminating either a red (for 'fail') or a green (for 'pass') LED indicator on the response panel. If a permanent record is required the result could be punched on a card, although this would increase the cost. The master reset function could then be achieved by arranging for the card to break a light beam (using a photon-coupled interrupter module) when it is inserted at the beginning of the test.

In the clinical trials described above the Elidice was used to determine whether a given clinically predetermined standard of visual acuity (in this case 1.0) was met. While a predetermined standard is universal in the case of driving test requirements, individual variations can be allowed for in the case of laser workers by so adjusting the visual angle of the Landolt-C on the apparatus as to make it appropriate to their clinically determined visual acuity. This can be done optically-for example, with two simple concave lenses-or geometrically by varying the viewing distance.

We thank Miss Janet Silver, Moorfields Eye Hospital, and her staff for help in supplying observers for the clinical trials, and the staff and patients for their co-operation.

References

Coltheart, M., Hull, E., and Slater, D. (1975). Nature, 253, 438-440.

Crossman, E. R. F. W., Goodeve, P. J., and Marg, E. (1970). American Journal of Optometry and Archives of American Academy of Optometry, 47, 344-355.

Decker, T. A., Kuether, C. L., Williams, R. E., and Logar, N. D. (1975). Archives of Ophthalmology, 93, 841-844.

Landolt, E. (1899). Archives d'Ophtalmologie et Revue Générale d'Ophtalmologie, 19, 465-471.

Stuart, J. A., and Burian, H. M. (1962). American Journal of Ophthalmology, 53, 471-477. 